\title{
Simultaneous topography-guided PRK followed by corneal collagen cross-linking after lamellar keratoplasty for keratoconus
}

This article was published in the following Dove Press journal:

Clinical Ophthalmology

31 October 2012

Number of times this article has been viewed

\author{
Leopoldo Spadea' \\ Marino Paroli ${ }^{2}$ \\ 'University of L'Aquila, Department \\ of Biotechnological and Applied \\ Clinical Sciences, Eye Clinic, L’Aquila, \\ ${ }^{2}$ La Sapienza University, Department \\ of Biotechnology and Medical-Surgical \\ Sciences, Latina, Italy
}

Background: The purpose of this paper is to report the results of using combined treatment of customized excimer laser-assisted photorefractive keratectomy (PRK) and prophylactic corneal collagen crosslinking (CXL) for residual refractive error in a group of patients who had previously undergone lamellar keratoplasty for keratoconus.

Methods: The study included 14 eyes from 14 patients who had originally been treated for keratoconus in one eye by excimer laser-assisted lamellar keratoplasty (ELLK), and subsequently presented with residual ametropia $(-6.11 \mathrm{D} \pm 2.48$, range -2.50 to -9.50$)$. After a mean $40.1 \pm 12.4$ months since ELLK they underwent combined simultaneous corneal regularization treatment with topographically guided transepithelial excimer laser PRK (central corneal regularization) and corneal CXL induced by riboflavin-ultraviolet $\mathrm{A}$.

Results: After a mean $15 \pm 6.5$ (range 6-24) months, all eyes gained at least one Snellen line of uncorrected distance visual acuity (range 1-10). No patient lost lines of corrected distance visual acuity, and four patients gained three lines of corrected distance visual acuity. Mean manifest refractive spherical equivalent was $-0.79 \pm 2.09$ (range +1 to -3.0 ) $\mathrm{D}$, and topographic keratometric astigmatism was $5.02 \pm 2.93$ (range 0.8-8.9) D. All the corneas remained clear (haze $<1$ ).

Conclusion: The combination of customized PRK and corneal CXL provided safe and effective results in the management of corneal regularization for refractive purposes after ELLK for keratoconus.

Keywords: corneal collagen crosslinking, excimer laser-assisted lamellar keratoplasty, photorefractive keratectomy

\section{Introduction}

Visual rehabilitation after penetrating and lamellar keratoplasty has improved with advances in microsurgical techniques. However, 8\%-20\% of eyes have irregular postoperative astigmatism that cannot be corrected with spectacles or contact lenses. ${ }^{1}$ The presence of irregular anterior surfaces, often associated with large amounts of higher order aberrations, limits best spectacle-corrected visual acuity and visual quality. Among the various techniques proposed for correcting post keratoplasty astigmatism, laser-assisted in situ keratomileusis (LASIK) has been more encouraging, leading to greater reduction in preoperative astigmatism. ${ }^{2,3}$ The major disadvantages of LASIK are related to the creation of the lamellar flap. Complications include free, incomplete, irregular, thin, or button-holed flaps. Moreover, LASIK compared with photorefractive keratectomy (PRK) causes more reduction in the biomechanical stability of the cornea. Conventional surface ablation has shown some efficacy. However, postoperative compli-
Correspondence: Leopoldo Spadea

Via Benozzo Gozzoli 34,

$00 \mid 42$ Rome, Italy

Tel +39086231 967।

Fax +3908 623। 964I

Email Ispadea@cc.univaq.it 
cations such as unpredictable refractive outcomes, refractive regression, and corneal haze are commonly seen, limiting the use of PRK in these eyes. ${ }^{4,5}$ Customized excimer laser ablation appears to be a powerful technique for treating corneal irregularities. The efficacy and safety of topography-guided excimer laser PRK to improve irregular corneal profiles has been evaluated in various corneal diseases and postoperative conditions with irregular astigmatism, including after keratoplasty. ${ }^{6-8}$

Corneal ectasia after lamellar keratoplasty or PRK has only occasionally been reported, and its incidence has not been assessed. Traditional treatment for iatrogenic ectasia includes rigid gas permeable contact lenses and intracorneal ring segments, but the most frequent choice remains corneal transplantation. ${ }^{9}$ Several studies have reported on corneal collagen cross-linking (CXL) induced by riboflavin-ultraviolet A as a treatment for postoperative LASIK ectasia. ${ }^{10}$ Recently, we reported a case of a patient with corneal ectasia which developed after excimer laser-assisted lamellar keratoplasty (ELLK) for keratoconus and a secondary PRK for residual refractive error, where treatment with corneal CXL provided safe and effective management of the ectasia. ${ }^{11}$

The purpose of this study was to evaluate the efficacy, predictability, safety, and stability of combined treatment using customized excimer laser-assisted PRK and prophylactic CXL for residual refractive error in a group of patients who had previously undergone lamellar keratoplasty for keratoconus.

\section{Materials and methods}

Eyes with high ametropia and irregular astigmatism after ELLK was performed for keratoconus were included in this prospective noncomparative case series enrolled between January 2010 and January 2012. The study was approved by the ethics committee of the School of Medicine, University of L'Aquila, and comprised 14 eyes (10 right eyes and four left eyes) from 14 patients, with a mean manifest refractive spherical equivalent of $-6.11 \pm 2.48$ (range -2.50 to -9.50 ) $\mathrm{D}$ and a mean keratometric astigmatism of $5.57 \pm 3.52$ (range 0.80-11.20) D. All the patients were treated, after a mean follow-up of 40.1 months \pm 12.4 from ELLK, at the Eye Clinic of L'Aquila University by the same surgeon (LS). All patients gave their informed consent after the risks, benefits, and alternative treatment methods were explained. The study was conducted according to the principles of the Declaration of Helsinki and good clinical practice. All the patients had had ELLK at least 24 months earlier using a previously described technique, ${ }^{12}$ with suture removal at least 6 months before PRK. They had stable refraction for at least 6 months and were intolerant of contact lenses.

Each patient had complete eye examinations, including uncorrected distance visual acuity (UDVA), corrected distance visual acuity (CDVA), slit-lamp biomicroscopy, intraocular pressure, and fundus evaluation. Cycloplegic refraction was measured preoperatively and postoperatively using the fogging (high plus) technique. Pupillometric analysis was performed using a dynamic automated pupillometer (pMetrics, iVis Technologies, Taranto, Italy), and pupils larger than $7.5 \mathrm{~mm}$ under scotopic conditions were excluded. Corneal topography and corneal thickness were analyzed during each examination using a high resolution tomographer (Precisio, iVis Technologies) and computerized videokeratoscopy (Keratograph, Oculus Optikgeräte GmbH, Wetzlar, Germany). Four keratoscopic images were obtained from each eye, and the best one was chosen. Keratometric difference values of $3.0 \mathrm{~mm}$ were considered to be keratometric astigmatism. Corneal thickness was evaluated using a $50 \mathrm{MHz}$ ultrasound pachymeter (Corneo Gage Plus, Sonogage Inc, Cleveland, $\mathrm{OH}$ ), and corneal endothelial morphology was evaluated using noncontact endothelial specular microscopy (Seed SP500, Seed Co., Ltd., Tokyo, Japan). The endothelium was analyzed for quantitative (endothelial cell density, as cells $/ \mathrm{mm}^{2}$ ) and qualitative (coefficient of variation, as standard deviation cell area/mean cell area) parameters. Measurements were taken preoperatively and $3,6,12$, and 24 months after surgery.

\section{Surgical technique}

The iVis Suite integrated platform (iVis Technologies) was used to perform custom excimer laser-assisted PRK. The platform consists of a surgical planning software application (central corneal regularization, $\mathrm{i}$ Vis Technologies), a corneal morphology data source (Precisio), and a high-frequency excimer laser (iRES, iVis Technologies). Treatment began with the acquisition of two identical topographies, with a maximum difference of $3 \mathrm{~mm}$ between all the processed points in the $5.0 \mathrm{~mm}$ central zone of the cornea. This process provided reliable corneal surface data. Excimer laser photoablation was performed using a high-frequency excimer laser (Gaussian flying-spot $650 \mu \mathrm{m}, 1000 \mathrm{~Hz}, 193 \mathrm{~nm}$ ) under topical anesthesia (lidocaine 4\% drops). All ablation profiles were calculated with the corneal apex as the ablation center. This option creates a postoperative cornea surface symmetrical with respect to the preoperative morphology of the cornea, which will likely be more physiologically acceptable to the patient. Postoperative curvature of the 
cornea was obtained by combining two methods, ie, the cornea surface was standardized to the lowest preoperative keratometric reading by flattening the steepest axis, and the spherical component of the manifest refraction was added with a positive or negative sign to the standardized keratometric value to obtain the desired (ideal) postoperative surface. The system calculated the ablation profile as the difference within the optical zone between the ideal postoperative surface and the preoperative corneal shape, with the aim of minimizing corneal ablation, regularizing a small central cornea area, and enlarging the epithelium ablation up to $9 \mathrm{~mm}$ to perform subsequent standard CXL. The transition zone was automatically calculated by the central corneal regularization program to create a constant gradient of curvature over the 360 degrees of the corneal surface. All the ablation profiles were integrated with transepithelial treatment that compensates for removal of the epithelium, so a constant ablation depth was added to the customized ablation. Transepithelial customized refractive treatment standardizes the technique, making it no-touch surgery. After the ablation profile is transferred to the laser, it positions the laser beam and delivers the ablation at the correct location and depth with respect to the corneal plane. To accomplish this, the central corneal regularization program sends the coordinates of each ablation point to the laser using the pupil center as the only reference point. The maximum net mean ablation depth was $100.0 \pm 17.44$ (range $80-135$ ) $\mu \mathrm{m}$ and the minimum mean estimated residual stromal thickness was set at $463 \pm 89.6$ (range 411-569) $\mu \mathrm{m}$.

After application of pilocarpine 1\% drops, preirradiation corneal soaking for 15 minutes in riboflavin solution (Ricrolin ${ }^{\circledR}$, SOOFT Italia Spa, Montegiorgio, Italy) applied every 2.5 minutes for 30 minutes was performed, followed by exposure to a solid-state ultraviolet A illuminator (CBM, $\mathrm{X}$-linker; CSO, Florence, Italy) for 30 minutes, irradiating an area $9 \mathrm{~mm}$ in diameter (energy delivered $3 \mathrm{~mW} / \mathrm{cm}^{2}$ ). At the end of treatment, a therapeutic bandage soft contact lens was applied and ofloxacin drops three times a day for 2 weeks were prescribed. Topical corticosteroids (butyrate clobetasone $0.1 \%$ ) drops were also prescribed three times a day for one month and then subsequently tapered and titrated.

\section{Results}

No damage to the limbal region of the cornea was observed. Epithelial regrowth was complete after the fourth day of soft contact lens bandaging. No adverse effects were observed during re-epithelialization or during the follow-up period (mean 15 months \pm 6.5 ; range 6-24). The mean age of the
10 men and four women was $40.1 \pm 10.1$ (range 29-57) years. The patients' data are shown in Table 1. The number of eyes with a UDVA of 20/200 or better increased from 6 preoperatively to 14 postoperatively. No eye had a preoperative UDVA more than 20/100; after treatment, four eyes had 20/50 UDVA. All the eyes gained at least one Snellen line of UDVA, and these data remained stable during the follow-up period. No patient lost lines of CDVA. Four patients gained three lines of CDVA. The efficacy index (ratio between final UDVA and CDVA before PRK-CXL) was 0.575. The safety index (ratio between final CDVA and CDVA before PRK-CXL) was 1.400. The mean preoperative manifest refractive spherical equivalent was $-6.11 \pm 2.48$ (range -2.50 to -9.50$) \mathrm{D}$; at the last postoperative visit it was $-0.79 \pm 2.09$ (range +1.0 to -3.0 ) D. From 2-4 months, eight eyes were within $\pm 1.00 \mathrm{D}$ of the manifest refractive spherical equivalent. These data were stable at the last follow-up visit. Figure 1 shows the course of the mean manifest refractive spherical equivalent during the entire follow-up period. Mean preoperative topographic keratometric astigmatism was $5.57 \pm 3.52$ (range $0.8-11.2$ ) D; at the last postoperative visit it was $5.02 \pm 2.93$ (range $0.8-8.9$ ) D. The endothelial cell density remained unchanged from its pretreatment baseline value to the last follow-up visit (2109 versus 2082 cells $/ \mathrm{mm}^{2}$ ). No patient received secondary surgery. All corneas were clear and no patient presented with haze $>1$ postoperatively (Figure 2). Four patients reported glare and monocular diplopia, and one patient reported halos. All symptoms resolved after treatment. Figure 3 shows an example of preoperative and postoperative corneal topographies and the pattern of the excimer laser customized ablation.

\section{Discussion}

There is no published literature to date evaluating the effect of prophylactic CXL combined with PRK to correct residual refractive error in patients who have previously undergone lamellar keratoplasty for keratoconus. Prophylactic CXL may offer a significant benefit in patients with a personal history of keratoconus. Corneal ectasia is a rare complication of PRK, is more frequent after LASIK, and is characterized by progressive corneal thinning associated with loss of UDVA and often CDVA. ${ }^{913}$ On the basis of histological and structural findings, the pathophysiology of post-LASIK or post-PRK ectasia can best be explained by interlamellar biomechanical slippage (eg, interlamellar fracture) followed by subsequent interfibrillar biomechanical slippage (eg, interfibrillar fracture) as opposed to direct primary collagen fibril failure (eg, fibrillar fracture). This chronic biomechanical failure process 
Table I Preoperative and postoperative mean data of the patients who had simultaneous topography-guided PRK and CXL after ELLK

\begin{tabular}{|c|c|c|c|c|c|}
\hline & $\begin{array}{l}\text { Preop } \\
(n=14)\end{array}$ & $\begin{array}{l}3 \text { months } \\
(n=14)\end{array}$ & $\begin{array}{l}6 \text { months } \\
(n=14)\end{array}$ & $\begin{array}{l}12 \text { months } \\
(\mathrm{n}=12)\end{array}$ & $\begin{array}{l}24 \text { months } \\
(n=6)\end{array}$ \\
\hline \multicolumn{6}{|c|}{ UDVA (decimal) } \\
\hline Mean \pm SD & $0.07 \pm 0.07$ & $0.17 \pm 0.19$ & $0.23 \pm 0.14$ & $0.22 \pm 0.15$ & $0.20 \pm 0.17$ \\
\hline Range & $0.01,0.2$ & $0.1,0.3$ & $0.1,0.4$ & $0.1,0.4$ & $0.1,0.4$ \\
\hline$P$ value & & 0.216 & 0.019 & 0.037 & 0.109 \\
\hline \multicolumn{6}{|c|}{ CDVA (decimal) } \\
\hline Mean \pm SD & $0.4 \pm 0.27$ & $0.50 \pm 0.25$ & $0.54 \pm 0.25$ & $0.56 \pm 0.16$ & $0.47 \pm 0.15$ \\
\hline Range & $0.1,0.7$ & $0.3,0.9$ & $0.3,1$ & $0.3,0.7$ & $0.3,0.6$ \\
\hline$P$ value & & 0.486 & 0.334 & 0.231 & 0.690 \\
\hline \multicolumn{6}{|l|}{ MRSE (D) } \\
\hline Mean \pm SD & $-6.11 \pm 2.48$ & $-0.35 \pm 1.85$ & $-0.89 \pm 2.11$ & $-0.79 \pm 1.69$ & $-1.5 \pm 2.18$ \\
\hline Range & $-9.50,-2.50$ & $-3.0,+1.0$ & $-3.0,+1.0$ & $-2.8,+1.0$ & $-3.0,+1.0$ \\
\hline$P$ value & & $<0.001$ & 0.001 & 0.001 & 0.024 \\
\hline \multicolumn{6}{|c|}{ Keratometric Astigmatism (D) } \\
\hline Mean \pm SD & $5.57 \pm 3.52$ & $5.25 \pm 2.76$ & $5.16 \pm 2.88$ & $5.02 \pm 2.13$ & $3.40 \pm 3.29$ \\
\hline Range & $0.8,11.2$ & $0.9,8.7$ & $0.8,8.9$ & $0.8,8.9$ & $0.8,7.1$ \\
\hline$P$ value & & 0.977 & 0.816 & 0.745 & 0.390 \\
\hline \multicolumn{6}{|c|}{ Corneal thickness $(\mu \mathrm{m})$} \\
\hline Mean \pm SD & $581 \pm 84.6$ & $465 \pm 89.6$ & $47 I \pm 79.1$ & $470 \pm 78.2$ & $475 \pm 79.6$ \\
\hline Range & 497,739 & 409,578 & 414,596 & 412,596 & 415,598 \\
\hline$P$ value & & 0.028 & 0.033 & 0.033 & 0.103 \\
\hline \multicolumn{6}{|c|}{ ECD (cells $\left./ \mathrm{mm}^{2}\right)$} \\
\hline Mean \pm SD & $2109 \pm 155$ & $2074 \pm 110$ & $2083 \pm 119$ & $2092 \pm 113$ & $2092 \pm 108$ \\
\hline Range & 1945,2376 & 1937,2382 & $|928,240|$ & 1935,2375 & 1940,2394 \\
\hline$P$ value & & 0.171 & 0.429 & 0.488 & 0.580 \\
\hline \multicolumn{6}{|c|}{ Corneal endothelial CoV } \\
\hline \multicolumn{6}{|c|}{ (SD cell area/mean cell area) } \\
\hline Mean \pm SD & $26 \pm 7$ & $29 \pm 8$ & $28 \pm 7$ & $27 \pm 5$ & $28 \pm 5$ \\
\hline Range & 24,29 & 23,33 & 24,32 & 23,32 & 23,33 \\
\hline$P$ value & & 0.276 & 0.438 & 0.529 & 0.443 \\
\hline
\end{tabular}

Abbreviations: UDVA, uncorrected distance visual acuity; CDVA, corrected distance visual acuity; MRSE, manifest refractive spherical equivalent; ECD, Endothelial cell density; CoV, Coefficient of variation.

is similar to that of the interlamellar and interfibrillar slippage described with keratoconus. ${ }^{14}$ All of these ectatic corneal conditions appear to be the biological equivalent of a well known, chronic type of biomechanical failure process known as interfiber fracture. With the success observed for CXL in

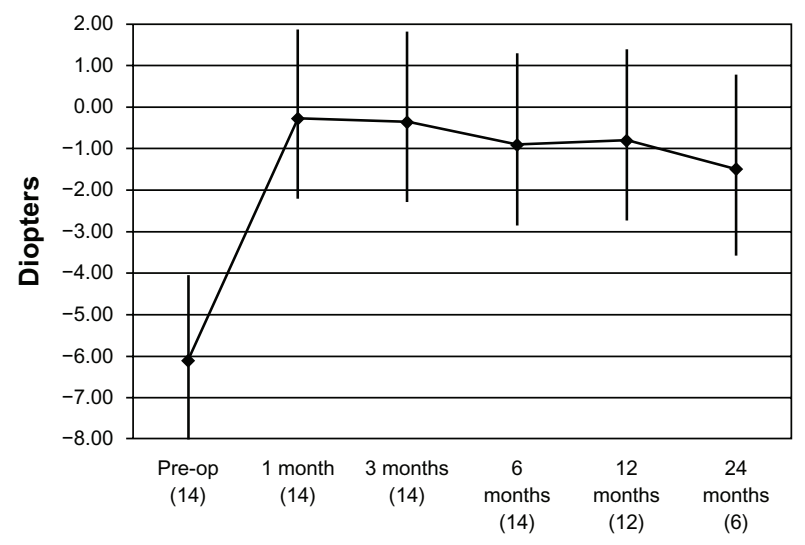

Figure I Mean manifest refractive spherical equivalent over the entire follow-up period (number of eyes). progressive keratoconus, some studies have also reported use of CXL for postoperative LASIK ectasia in very thin corneas. ${ }^{15}$ Specifically, formation of interfiber CXL through singlet oxygen reactivity leads to a stiffer, tougher collagen matrix that tends to maintain its rigidity over a period of several years. Recently, we reported the case of a patient who developed corneal ectasia after ELLK for keratoconus and secondary PRK for residual refractive error where the treatment of corneal CXL provided safe and effective management of the ectasia. ${ }^{11}$

Prophylactic CXL for high-risk LASIK cases was demonstrated to be a safe and effective adjunctive treatment for refractive regression and potential ectasia. ${ }^{16}$ This may be viewed as prophylactic customization of the biomechanical behavior of corneal collagen.

Customized ablation was proven to be an effective, safe, and stable option for the treatment of irregular astigmatism from various etiologies. ${ }^{17}$ The principle is to minimize corneal surface irregularities that decrease visual quality. 

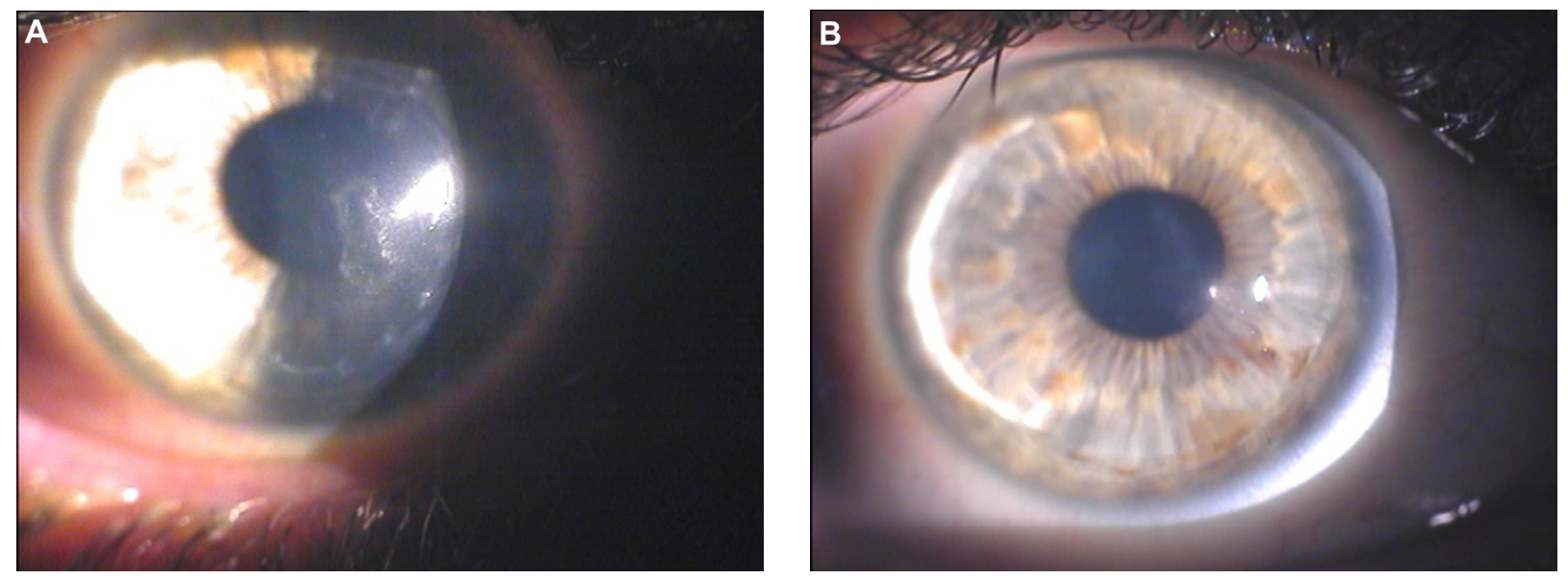

Figure 2 Biomicroscopic image of the right eye of a 29-year-old male patient. (A) Three years after excimer laser-assisted lamellar keratoplasty, a mild central scar secondary to delayed epithelial healing is visible. (B) Two years after customized photorefractive keratectomy and corneal collagen cross-linking with riboflavin and ultraviolet A irradiation, the central scar is considerably reduced and the overall corneal clarity appears improved.

The central corneal regularization software program was effective in reducing post-ELLK ametropia. In our series, mean correction of the spherical equivalent refractive error was greatly reduced, with an improvement in UDVA in all patients. Only two myopic patients had a mild overcorrection of 1.0 D. No patient lost any lines of CDVA. The manifest refractive spherical equivalent was reduced in all patients to a statistically significant extent, with no regression 12 months postoperatively. This was supported by the safety and efficacy indices. The apparent change in refraction and in keratometric astigmatism between 12 and 24 months of follow-up is related to the different number of eyes evaluated (12 versus 6). All corneas were clear, with no significant stromal haze.
In surface excimer laser treatment, customized ablation to smooth the corneal surface should provide better results. In fact, ablating only the localized defect in a small central area removes less tissue than correcting a similar amount of regular astigmatism. This sparing of the corneal tissue allows treatment of high levels of irregular astigmatism, simultaneously achieving a regular smooth surface. Even if the eye is undercorrected, visual acuity is improved by smoothing the corneal surface.

Truly customized treatment of transplanted corneas is possible only on the epithelium. In fact, the different thickness and morphology, together with the different pattern of re-epithelialization of these corneas, can affect the efficacy

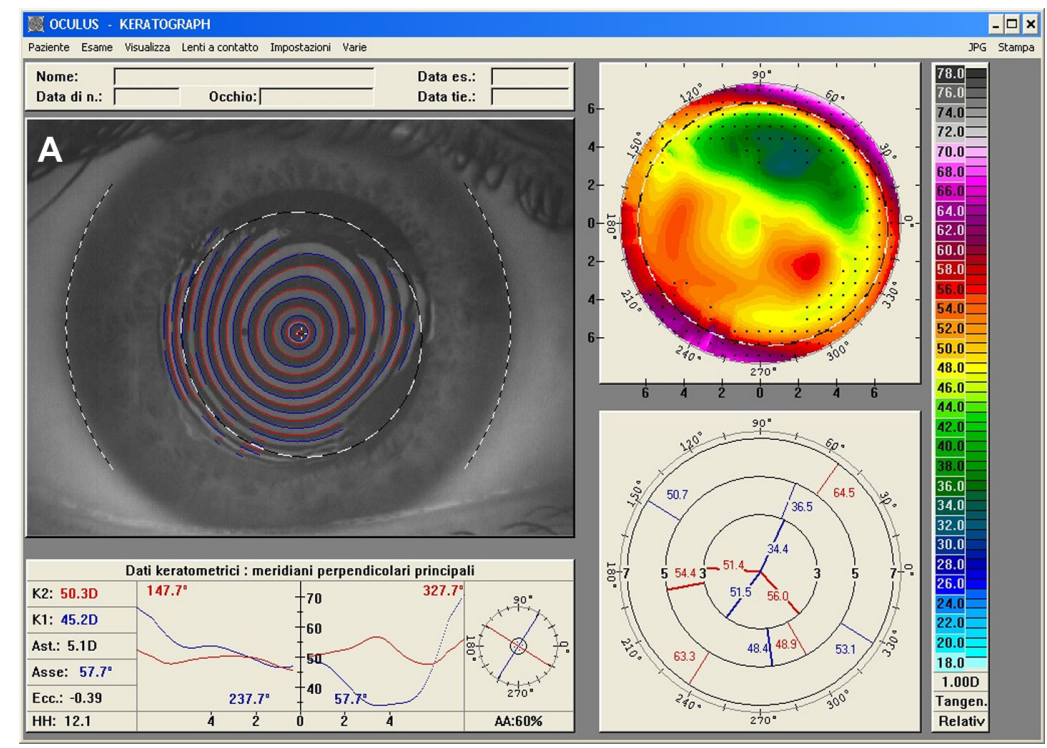

Figure 3 (Continued) 

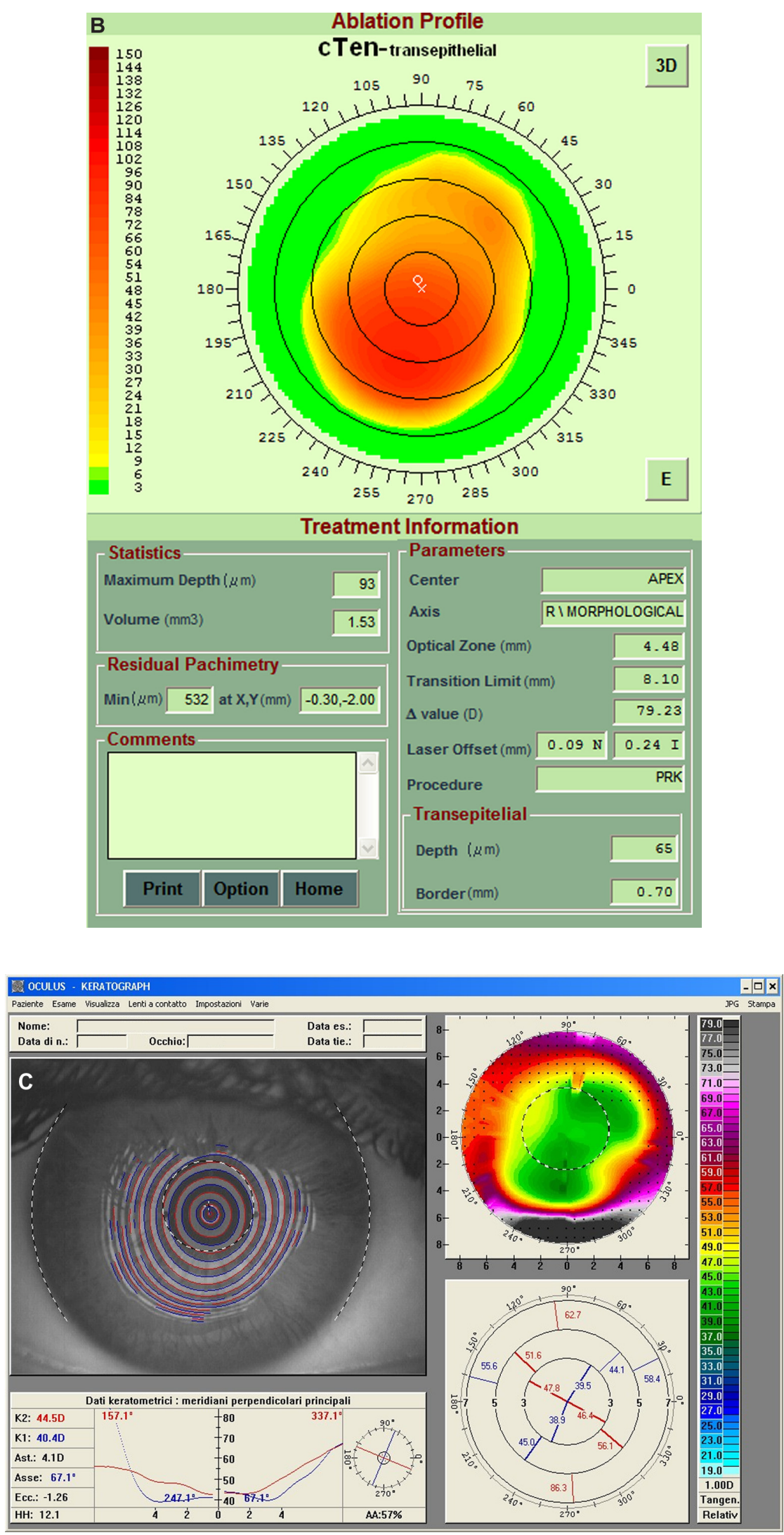

Figure 3 (A) Right eye videokeratographic map in a 34-year-old female patient before treatment. The topographic pattern highlights irregular astigmatism (relative scale, tangential algorithm). (B) Pattern of transepithelial customized ablation. (C) Right eye videokeratographic map 2 years after customized photorefractive keratectomy and corneal collagen cross-linking with riboflavin and ultraviolet $\mathrm{A}$ irradiation. The topographic pattern showed an improvement in the corneal profile, with central flattening (relative scale, tangential algorithm). 
of customization. ${ }^{18}$ In addition, our data seem to confirm that treating the epithelium directly is better than treating after epithelial debridement. ${ }^{19}$ One explanation is that customized transepithelial PRK regularizes stromal and epithelial defects, which may be important for visual acuity and final refraction in transplanted eyes. In addition, manually removing the epithelium may affect the final refractive result. The trauma of removing the epithelium from the underlying cornea may disrupt the original keratoplasty wound, inducing unquantifiable amounts of astigmatism. ${ }^{20}$

In this small study, we established that prophylactic CXL is safe. We had seen no secondary ectasia, adverse effects, or significant overcorrection in any of our patients, nor any significant unpredicted refractive result. Of course, one would wonder why there is a need for prophylactic CXL when corneal ectasia is a rare occurrence. Nonetheless, this concept should be evaluated in larger studies to establish if this intervention offers a more stable excimer laser ablation effect, which has shown surprising changes in a large proportion of patients in several long-term studies.

In conclusion, the combination of customized excimer laser-assisted PRK and prophylactic corneal CXL was safe and effective in the management of corneal regularization for refractive purposes after ELLK for keratoconus. However, the efficacy of this technique in the long term needs to be assessed in future studies with a greater number of patients.

\section{Acknowledgment}

Financial support for this study was received from the Department of Biotechnological and Applied Clinical Sciences, University of L'Aquila, L'Aquila, Italy.

\section{Disclosure}

The authors have no financial or proprietary interest in any product or company cited in this manuscript.

\section{References}

1. De Molfetta V, Brambilla M, De Casa N, Arpa P, Riva M. Residual corneal astigmatism after perforating keratoplasty. Ophthalmologica. 1979;179:316-321.

2. Hardten DR, Chittcharus A, Lindstrom RL. Long term analysis of LASIK for the correction of refractive errors after penetrating keratoplasty. Cornea. 2004;23:479-489.

3. Spadea L, Saviano BM, Di Gregorio A, Di Lodovico D, De Sanctis F. Topographically guided two steps LASIK and standard LASIK in the correction of refractive errors after penetrating keratoplasty. Eur J Ophthalmol. 2009;19:535-543.
4. Bilgihan K, Ozdek SC, Akata F, Hasanreisoglu B. Photorefractive keratectomy for post-penetrating keratoplasty myopia and astigmatism. $J$ Cataract Refract Surg. 2000;26:1590-1595.

5. Solomon R, Donnenfeld ED, Perry HD. Photorefractive keratectomy with mitomycin $\mathrm{C}$ for the management of a LASIK flap complication following a penetrating keratoplasty. Cornea. 2004;23:403-405.

6. Spadea L, Bianco G, Balestrazzi E. Topographically guided excimer laser photorefractive keratectomy to treat superficial corneal opacities. Ophthalmology. 2004;111:458-462.

7. La Tegola MG, Alessio G, Sborgia C. Topographic customized photorefractive keratectomy for regular and irregular astigmatism after penetrating keratoplasty using the LIGI CIPTA/Laser-Sight platform. J Refract Surg. 2007;23:681-693.

8. Pedrotti E, Sbabo A, Marchini G. Customized transepithelial photorefractive keratectomy for iatrogenic ametropia after penetrating or deep lamellar keratoplasty. J Cataract Refract Surg. 2006;32: 1288-1291.

9. Randleman JB. Post-laser in-situ keratomileusis ectasia: current understanding and future directions. Curr Opin Ophthalmol. 2006;17: 406-412.

10. Hafezi F, Kanellopoulos J, Wiltfang R, Seiler T. Corneal collagen crosslinking with riboflavin and ultraviolet A to treat induced keratectasia after laser in situ keratomileusis. $J$ Cataract Refract Surg. 2007;33: 2035-2040.

11. Spadea L. Collagen crosslinking for ectasia following PRK performed in excimer laser-assisted keratoplasty for keratoconus. Eur J Ophthalmol. 2012;22:274-277.

12. Spadea L, Gizzi R, Evangelista Conocchia N, Urbano S. Optical pachimetry-guided customized excimer laser-assisted lamellar keratoplasty for the surgical treatment of keratoconus. J Cataract Refract Surg. 2012;38:1559-1567.

13. Spadea L, Cantera E, Cortes M, Evangelista Conocchia N, Stewart CW. Corneal ectasia after myopic laser in situ keratomileusis: a long term study. Clin Ophthalmol. 2012;6:1801-1813.

14. Caporossi A, Baiocchi S, Mazzotta C, Traversi C, Caporossi T. Parasurgical therapy for keratoconus by riboflavin-ultraviolet type A rays induced cross-linking of corneal collagen: preliminary refractive results in an Italian study. $J$ Cataract Refract Surg. 2006;32:837-845.

15. Spadea L, Mencucci R. Transepithelial corneal collagen cross-linking in ultrathin keratoconic corneas. Clin Ophthalmol. 2012;6:1785-1792.

16. Kanellopoulos AJ. Long-term safety and efficacy follow-up of prophylactic higher fluence collagen cross-linking in high myopic laser-assisted in situ keratomileusis. Clin Ophthalmol. 2012;6: $1125-1130$.

17. Alessio G, Boscia F, La Tegola MG, Sporgia C. Topographydriven photorefractive keratectomy; results of corneal interactive programmed topographic ablation software. Ophthalmology. 2000;107: $1578-1587$.

18. Meyer RF, Bobb KC. Corneal epithelium in penetrating keratoplasty. Am J Ophthalmol. 1980;90:142-147.

19. Alessio G, Boscia F, La Tegola MG, Sborgia C. Corneal interactive programmed topographic ablation customized photorefractive keratectomy for correction of post-keratoplasty astigmatism. Ophthalmology. 2001;108:2029-2037.

20. Lazzaro DR, Haight DH, Belmont SC, Gibralter RP, Aslanides IM, Odrich MG. Excimer laser keratectomy for astigmatism occurring after penetrating keratoplasty. Ophthalmology. 1996;103:458-464. 


\section{Publish your work in this journal}

Clinical Ophthalmology is an international, peer-reviewed journal covering all subspecialties within ophthalmology. Key topics include: Optometry; Visual science; Pharmacology and drug therapy in eye diseases; Basic Sciences; Primary and Secondary eye care; Patient Safety and Quality of Care Improvements. This journal is indexed on

Submit your manuscript here: http://www.dovepress.com/clinical-ophthalmology-journal
PubMed Central and CAS, and is the official journal of The Society of Clinical Ophthalmology (SCO). The manuscript management system is completely online and includes a very quick and fair peer-review system, which is all easy to use. Visit http://www.dovepress.com/ testimonials.php to read real quotes from published authors. 